\title{
Serum Y-Box Binding Protein 1 (YBX-1) and Interleukin 6 (IL-6) Are Associated with Metastasis in Breast Cancer Patients
}

\author{
Caroline K. Abd-Elaziz ${ }^{1}$, Nadia A. Abd El Moneim² ${ }^{2}$, Shaymaa E. El Feky ${ }^{3 *}$, Amira M. Arafat ${ }^{1}$ \\ ${ }^{1}$ Department of Zoology, Faculty of Science, Damanhour University, Damanhour, Egypt \\ ${ }^{2}$ Department of Cancer Management and Research, Medical Research Institute, Alexandria University, Alexandria, Egypt \\ ${ }^{3}$ Department of Radiation Sciences, Medical Research Institute, Alexandria University, Alexandria, Egypt \\ Email: *shaymaa.elfeky@alexu.edu.eg
}

How to cite this paper: Abd-Elaziz, C.K., El Moneim, N.A.A., El Feky, S.E. and Arafat, A.M. (2019) Serum Y-Box Binding Protein 1 (YBX-1) and Interleukin 6 (IL-6) Are Associated with Metastasis in Breast Cancer Patients. Advances in Breast Cancer Research, 8, 119-134.

https://doi.org/10.4236/abcr.2019.83009

Received: June 12, 2019

Accepted: July 12, 2019

Published: July 15, 2019

Copyright $\odot 2019$ by author(s) and Scientific Research Publishing Inc. This work is licensed under the Creative Commons Attribution International License (CC BY 4.0).

http://creativecommons.org/licenses/by/4.0/

(c) (i) Open Access

\begin{abstract}
Objectives: The aim of this study was to assess the levels of Y-box binding protein 1 (YBX-1) and interleukin 6 (IL-6) in the sera of metastatic and non-metastatic breast cancer patients (BC), investigate their clinicopathological significance and to analyze their potential use as biomarkers of breast cancer metastasis. Methods: The study included ninety subjects sub-grouped equally into metastatic $B C$, non-metastatic $B C$ and healthy volunteers. Serum YBX-1 and IL-6 were quantified using ELISA technique while CA 15-3 was quantified using IRMA kit. Clinical data were collected from patients' records. Results: YBX-1 ( $\mathrm{p}<0.001)$, IL-6 ( $<<0.001)$ and CA15-3 ( $\mathrm{p}=0.017,0.001)$ were significantly elevated in metastatic and non-metastatic $\mathrm{BC}$ patients compared to healthy controls, however, only YBX-1 ( $\mathrm{p}<0.001)$ and IL-6 (p $<$ 0.001 ) showed a significant difference with cancer metastasis. Generally, YBX-1 and IL-6 were correlated with worse histological grade and late clinical stage in breast cancer patients and they were also associated with axillary lymph nodes involvement and positive vascular invasion in metastatic BC patients. Serum YBX-1 and IL-6 levels were positively correlated to each other $\left(\mathrm{r}_{\mathrm{s}}=\right.$ $0.615, \mathrm{p}<0.001)$ and they showed high sensitivity and specificity compared to CA $15-3$ ( $\mathrm{p}<0.001$ and $\mathrm{p}=0.004$ for YBX-1 and IL-6 respectively) for predicting cancer metastasis. Conclusions: Serum YBX-1 and IL- 6 are potential biomarkers of breast cancer patients with significant correlation with bad clinicopathological characteristics. Serum YBX-1 and IL-6 have superior sensitivity and specificity compared to CA15-3 and can serve as potential follow up and prognostic markers.
\end{abstract}

\section{Keywords}

Breast Cancer, Metastasis, Y-Box Binding Protein 1, Interleukin-6, Biomarker 


\section{Introduction}

Breast cancer (BC) is the most commonly diagnosed female-associated malignancy with an incidence rate of more than 2 million in 2018. Breast cancer is also the leading cause of cancer death in women which is mainly attributed to cancer metastasis [1]. Good management of metastatic BC requires reliable biomarkers that aid in evaluation of tumor burden and determine response to treatment protocols. Y-Box binding protein 1 (YBX-1) is an evolutionary conserved cold shock pleotropic protein that belongs to the Y-box transcription factors [2]. These classes of proteins are identified by their ability to regulate the gene expression by binding to the Y-box promotor region [3]. Many reports have highlighted the role of YBX-1 in the regulation of vital processes including DNA replication [4], repair [5] and transcription [6] as well as mRNA splicing [7] and translation [8]. YBX-1 was also found to be dysregulated in many types of cancer including cervical [9], ovarian [10], gastric [11] and colorectal [12]. Strong evidence has supported the role of YBX-1 in carcinogenesis related events including uncontrolled cell proliferation, genomic instability, cell immortality and induction of angiogenesis [13] [14]. In breast cancer (BC), YBX-1 is linked to drug resistance and promotion of tumor invasion and metastasis through enhanced epithelial-to-mesenchymal transition (EMT) [15] [16].

Tumor microenvironment is usually characterized by an abnormal release of proinflammatory cytokines, which plays an important role in cancer metastasis [17]. Of the important cytokines involved in this process, interleukin 6 (IL-6) have been linked with induction of drug resistance, stem cell like characteristics and EMT induced metastasis in breast cancer [18] [19] [20]. Interestingly, few number of breast cancer studies have suggested that YBX-1 interacts with IL-6 creating a positive feed-forward loop driving EMT-like metastatic properties during cancer progression [21].

Despite the strong evidence of YBX-1 role in breast cancer invasion and metastasis, it's clinical significance and association with clinicopathological characteristics is not been thoroughly investigated yet. Herein, we conducted this study to assess the serum levels of YBX-1, IL-6 as well as the traditional follow-up marker, cancer antigen 15-3 (CA 15-3) in metastatic and non-metastatic breast cancer patients. Furthermore, we analyzed the association and correlation of all markers with patients' clinicopathological characteristics.

\section{Materials and Methods}

\subsection{Study Population and Design}

The current study included ninety subjects. Sixty female BC patients aged between 30 and 73 years from those referred to Cancer Management and Research Department, Medical Research Institute, University of Alexandria, Egypt from 2012 to 2018. Enrolled patients were selected from those who had no history of any type of malignancy and didn't receive neoadjuvant treatment then they were 
subdivided into metastatic and non-metastatic groups ( $\mathrm{n}=30$ each). The study also included thirty healthy female volunteers with matched age.

Cancer treatment was received according to physician description. The majority of patients (75\%) received postoperative radiotherapy followed by 6 cycles of FAC (5-Fluorouracil, Adriamycin and Cyclophosphamide). While for the rest of patients, radiotherapy was supplied after finishing the last chemotherapy cycle. Demographic and clinicopathological data were collected from pathology reports and patients' follow-up records which included: age, family history, menopausal status, hormone receptors' status (semi-quantified by immunohistochemistry), histological grade, vascular invasion, tumor size, lymph nodes involvement, clinical stage, and site of metastasis (where applicable).

Ethical approvals for subjects' recruitment were obtained from the local Ethics Committee of Medical Research Institute, University of Alexandria and informed consents were obtained from all subjects. The study was conducted in accordance with the Declaration of Helsinki and good clinical practice guidelines.

\subsection{Quantitative Determination of YBX-1, IL-6 and CA 15-3 Serum Levels}

A peripheral blood sample was collected from all subjects in plain vacutainer tubes. Separation of serum was done by centrifugation at $2000 \mathrm{~g}$ for $10 \mathrm{~min}$ at $4^{\circ} \mathrm{C}$. Serum was then aliquoted and stored at $-80^{\circ} \mathrm{C}$ till use and repeated freeze and thaw cycles were avoided. Enzyme-linked immunosorbent assay (ELISA) kits were used to quantify both YBX-1 (Cloud-Clone Corp., USA) and IL-6 (Invitrogen, Thermo. Fisher Scientific, USA) while immunoradiometric assay (IRMA) was used to quantify CA 15-3 (Diasource Immunoassays S.A., Belgium) according to manufacturers' instructions. For ELISA kits, absorbance at $450 \mathrm{~nm}$ was measured in an InfiniteM200 Plate Reader (Tecan). For CA 15-3 IRMA kit, radioactivity was measured using Wizard2 2470 automatic gamma counter (Perkin Elmer Inc., USA).

\subsection{Statistical Analysis}

Data were analyzed using SPSS software package version 20.0 (IBM Corporation, Chicago, Illinois, USA). Quantitative data were described using mean \pm standard error mean. The distributions of quantitative variables were tested for normality using Kolmogorov-Smirnov test. Mann-Whitney test was used to compare between two studied groups, and Kruskal Wallis test was used to compare between more than two groups. Spearman correlation test was used to study the correlation between YBX-1, IL- 6 and CA 15.3 serum concentrations and the clinicopathological parameters, also used to correlate YBX-1 and IL-6 concentrations. Receiver operating characteristic (ROC) curve was done to interpret the sensitivity and specificity of YBX-1 and IL- 6 against CA 15-3 for predicting BC metastasis. At all statistical analyses, $p$ value was considered significant at $\leq 0.05$. 


\section{Results}

\subsection{Patients' Characteristics}

The clinicopathological characteristics of all enrolled BC patients are presented in Table 1 . The majority of enrolled patients were post-menopausal with negative family history of breast cancer. All patients were diagnosed with invasive ductal carcinoma and underwent modified radical mastectomy. Two-thirds of patients had a tumor size less than $5 \mathrm{~cm}$ and their lymph node involvement ranged from N0 to $\mathrm{N} 3$ with percentages $23.3 \%, 41.7 \%, 5 \%, 30 \%$ respectively. Regarding hormone receptor status, most patients had varying degrees of $\mathrm{ER} \alpha / \mathrm{PR}$ positive expression though almost $60 \%$ lacked Her2/neu receptor expression. The majority of patients had histological grade II whilst $50 \%$ of patients presented with clinical stage IV as well as metastasis. The site of metastasis varied between bone (30\%), lung (26.7\%), liver (20\%) and other distant sites. Regarding hormonereceptor expression.

\subsection{Serum Levels of YBX-1, IL-6 and CA 15-3 in Metastatic BC, Non-Metastatic BC and Healthy Controls}

Data presented in Figure 1 shows the values of YBX-1, IL-6 and CA 15-3 in metastatic BC, non-metastatic BC and control groups. The median serum YBX-1 level was $11.15 \pm 3.86 \mathrm{pg} / \mathrm{ml}$ in metastatic $\mathrm{BC}$ patients and $7.53 \pm 1.12 \mathrm{pg} / \mathrm{ml}$ in

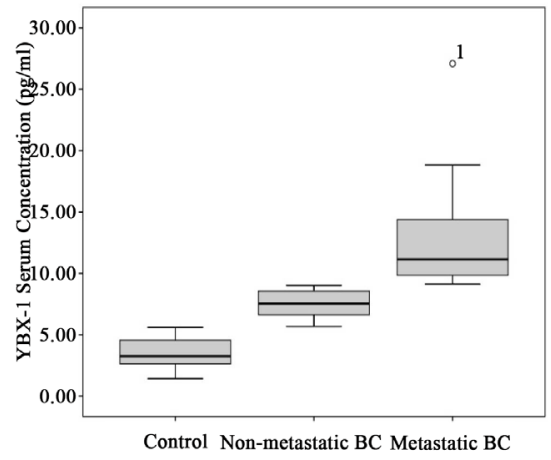

(a)

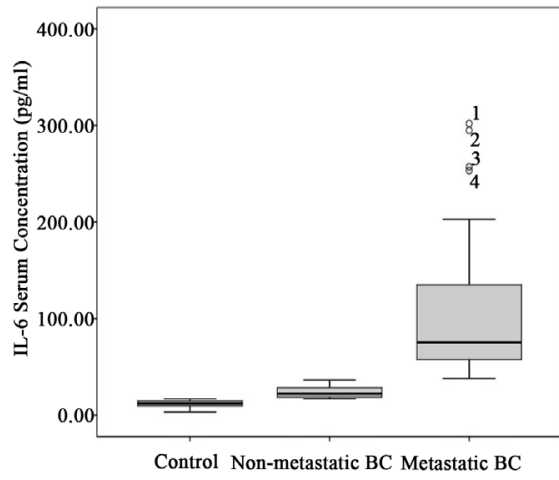

(b)

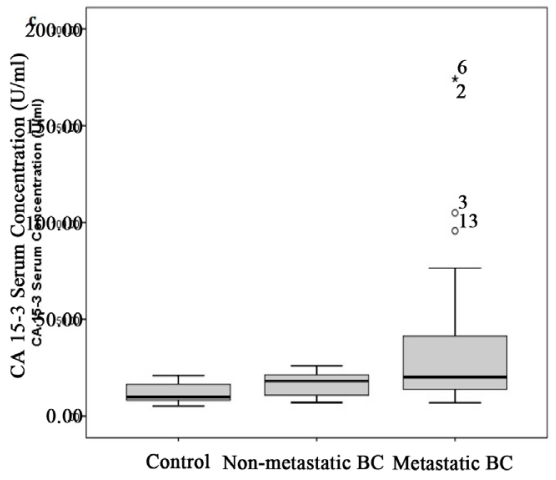

(c)

Figure 1. Quantitative levels of (a) YBX-1; (b) IL-6 and (c) CA 15-3 in metastatic BC, non-metastatic $\mathrm{BC}$ and control groups. 
Table 1. Clinicopathological parameters of breast cancer patients.

\begin{tabular}{|c|c|c|}
\hline \multirow{2}{*}{ Clinicopathological Characteristics } & \multicolumn{2}{|c|}{ BC Patients } \\
\hline & No. & $\%$ \\
\hline Age & & \\
\hline \multicolumn{3}{|l|}{ Menopausal Status } \\
\hline Pre-menopausal & 13 & $21.7 \%$ \\
\hline Post-menopausal & 47 & $78.3 \%$ \\
\hline \multicolumn{3}{|l|}{ Family History } \\
\hline Negative & 51 & $85 \%$ \\
\hline Positive & 9 & $15 \%$ \\
\hline \multicolumn{3}{|l|}{ Type of Surgery } \\
\hline Modified Radical Mastectomy & 60 & $100 \%$ \\
\hline \multicolumn{3}{|l|}{ Tumor Type } \\
\hline Invasive Ductal Carcinoma & 60 & $100 \%$ \\
\hline \multicolumn{3}{|l|}{ Estrogen Receptor (ER $\alpha$ ) Expression } \\
\hline- & 7 & $11.7 \%$ \\
\hline+ & 20 & $33.3 \%$ \\
\hline++ & 25 & $41.7 \%$ \\
\hline+++ & 8 & $13.3 \%$ \\
\hline \multicolumn{3}{|l|}{ Progesterone Receptor (PR) Expression } \\
\hline- & 10 & $16.7 \%$ \\
\hline+ & 24 & $40 \%$ \\
\hline++ & 20 & $33.3 \%$ \\
\hline+++ & 6 & $10 \%$ \\
\hline \multicolumn{3}{|l|}{ Her2/neu Expression } \\
\hline- & 35 & $58.4 \%$ \\
\hline+ & 8 & $13.3 \%$ \\
\hline++ & 8 & $13.3 \%$ \\
\hline+++ & 5 & $8.3 \%$ \\
\hline Unknown & 4 & $6.7 \%$ \\
\hline \multicolumn{3}{|l|}{ Tumor size $(\mathrm{Cm})$} \\
\hline $\mathrm{T} 1(\leq 2)$ & 17 & $28.3 \%$ \\
\hline $\mathrm{T} 2(2-\leq 5)$ & 37 & $61.7 \%$ \\
\hline T3 $(>5)$ & 6 & $10 \%$ \\
\hline \multicolumn{3}{|l|}{ Lymph Nodes Involvement } \\
\hline No & 14 & $23.3 \%$ \\
\hline N1 $(1-3)$ & 25 & $41.7 \%$ \\
\hline $\mathrm{N} 2(4-9)$ & 3 & $5 \%$ \\
\hline N3 $(>9)$ & 18 & $30 \%$ \\
\hline
\end{tabular}




\section{Continued}

\begin{tabular}{|c|c|c|}
\hline \multicolumn{3}{|c|}{ Vascular Invasion } \\
\hline- & 2 & $3.3 \%$ \\
\hline+ & 58 & $96.7 \%$ \\
\hline \multicolumn{3}{|c|}{ Histological Grade } \\
\hline II & 55 & $91.7 \%$ \\
\hline III & 5 & $8.3 \%$ \\
\hline \multicolumn{3}{|l|}{ Clinical Stage } \\
\hline I & 1 & $1.7 \%$ \\
\hline II & 18 & $30 \%$ \\
\hline III & 11 & $18.3 \%$ \\
\hline IV & 30 & $50 \%$ \\
\hline \multicolumn{3}{|l|}{ Metastasis } \\
\hline No metastasis & 30 & $50 \%$ \\
\hline Metastasis & 30 & $50 \%$ \\
\hline \multicolumn{3}{|l|}{ Site of Metastasis } \\
\hline Bone & 9 & $30 \%$ \\
\hline Lung & 8 & $26.7 \%$ \\
\hline Liver & 6 & $20 \%$ \\
\hline Other sites & 7 & $23.3 \%$ \\
\hline
\end{tabular}

non-metastatic patients which was significantly higher than its level in control group $(3.26 \pm 1.33 \mathrm{pg} / \mathrm{ml})$ with $\mathrm{p}$ values of $<0.001$. The YBX-1 level in metastatic BC patients was also significantly higher than its levels in non-metastatic patients ( $\mathrm{p} \leq 0.001)$. Similar pattern was also observed in IL-6 levels in all studied groups where its median value $75.48 \pm 14.22 \mathrm{pg} / \mathrm{ml}$ in metastatic group and $22.21 \pm 5.70 \mathrm{pg} / \mathrm{ml}$ in non-metastatic groups. Again, both groups were significantly elevated compared to the $12.00 \pm 3.30 \mathrm{pg} / \mathrm{ml}$ level of control group ( $\mathrm{p} \leq$ 0.001). IL-6 was also significantly elevated in metastatic than non-metastatic patients ( $\mathrm{p} \leq 0.001$ ). Regarding CA 15-3 serum levels, its median values in metastatic $(20.10 \pm 44.24 \mathrm{pg} / \mathrm{ml})$ and non-metastatic $(18.21 \pm 5.88)$ groups were significantly elevated than control group $(16.00 \pm 7.39)$ ( $\mathrm{p}=0.017$ and 0.001 respectively), however, it failed to differentiate between both cancer patients' groups $(\mathrm{p}=0.442)$.

\subsection{Correlations of YBX-1, IL-6 and CA 15-3 with Clinicopathological Characteristics}

Stratification analysis revealed that serum levels of YBX-1, IL-6 and CA 15-3 in all breast cancer patients $(n=60)$ with clinicopathological parameters are represented in Table 2. CA 15-3 didn't show any significant association or correlation with all clinicopathological parameters. On the other hand, YBX-1 and 
Table 2. Stratification analysis of Y-Box1, IL-6, and CA 15.3 in patients with different clinicopathological status.

\begin{tabular}{|c|c|c|c|c|}
\hline & No. & Y-Box1 & IL-6 & CA 15.3 \\
\hline \multicolumn{5}{|l|}{ Menopausal } \\
\hline Pre & 13 & $8.64(5.75-12.97)$ & $43.10(17.22-99.83)$ & $21.16(7.15-56.34)$ \\
\hline Post & 47 & $10.44(5.68-27.1)$ & $74.01(16.78-302)$ & $30.05(0.02-174.23)$ \\
\hline $\mathrm{U}(\mathrm{p})$ & & $228.5(0.167)$ & $229(0.170)$ & $303.5(0.971)$ \\
\hline \multicolumn{5}{|l|}{ ER } \\
\hline- & 7 & $10.30(6.22-18.84)$ & $79.7(18.52-295.04)$ & $47.77(10.20-174.23)$ \\
\hline+ & 20 & $9.64(5.73-27.10)$ & $63.46(16.78-302)$ & $18.22(7.02-41.34)$ \\
\hline++ & 24 & $10.76(5.68-18.49)$ & $74.54(16.78-257.22)$ & $33.36(7.43-174.23)$ \\
\hline+++ & 8 & $8.82(6.79-11.72)$ & $40.70(19.39-81.57)$ & $20.18(7.15-42.69)$ \\
\hline$H(p)$ & & $3.77(0.288)$ & $3.89(0.273)$ & $2.14(0.545)$ \\
\hline \multicolumn{5}{|l|}{ PR } \\
\hline- & 10 & $11.54(6.22-27.10)$ & $91.17(18.52-302)$ & $39.04(10.2-174.23)$ \\
\hline+ & 23 & $9.87(5.75-18.49)$ & $59.22(17.22-257.22)$ & $23.00(7.43-105.01)$ \\
\hline++ & 20 & $9.92(5.68-15.94)$ & $71.85(16.78-253.3)$ & $29.16(7.02-174.23)$ \\
\hline+++ & 6 & $8.78(5.68-27.10)$ & $38.45(19.39-69.83)$ & $26.48(10.75-174.23)$ \\
\hline$H(p)$ & & $0.50(0.919)$ & $0.59(0.899)$ & $4.87(0.181)$ \\
\hline \multicolumn{5}{|l|}{ Her2/neu } \\
\hline- & 35 & $10.15(5.73-27.1)$ & $64.62(16.78-302)$ & $27.67(7.02-174.23)$ \\
\hline+ & 8 & $10.71(5.68-18.84)$ & $109.45(16.78-295.04)$ & $36.55(8.73-174.23)$ \\
\hline++ & 8 & $8.59(6.06-12.9)$ & $29.55(17.22-59.83)$ & $16.60(7.15-39.03)$ \\
\hline+++ & 5 & $9.98(5.68-27.10)$ & $53.74(22.34-102)$ & $29.22(8.83-76.60)$ \\
\hline$H(p)$ & & $1.39(0.708)$ & $1.52(0.679)$ & $3.77(0.287)$ \\
\hline \multicolumn{5}{|l|}{ Tumor size } \\
\hline $\mathrm{T} 1(\leq 2)$ & 17 & $10.19(5.73-18.84)$ & $64.28(17.22-257.22)$ & $21.44(7.02-105.01)$ \\
\hline $\mathrm{T} 2(2-\leq 5)$ & 37 & $9.92(3.94-27.10)$ & $71.48(16.78-302.0)$ & $30.64(7.15-174.23)$ \\
\hline $\mathrm{T} 3(>5)$ & 6 & $9.77(6.76-15.94)$ & $50.19(18.52-88.52)$ & $32.62(14.68-95.76)$ \\
\hline $\mathrm{H}(\mathrm{p})$ & & $0.12(0.943)$ & $0.20(0.0 .905)$ & $2.44(0.0 .295)$ \\
\hline \multicolumn{5}{|c|}{ Lymph nodes involvement } \\
\hline No & 13 & $8.94(7.37-10.80)$ & $47.02(20.70-128.96)$ & $20.87(8.83-42,69)$ \\
\hline N1 (1 - 3) & 24 & $9.06(5.68-12.99)$ & $44.45(16.78-102)$ & $22.81(7.02-95.76)$ \\
\hline N2 $(3-9)$ & 3 & $7.32(6.22-8.02)$ & $21.57(18.52-23.74)$ & $19.01(14.68-23.28)$ \\
\hline N3 $(>9)$ & 19 & $12.49(6.06-27.10)$ & $111.86(17.22-302.0)$ & $42.03(7.43-174.23)$ \\
\hline$H(p)$ & & $5.32(0.150)$ & $5.30(0.151)$ & $0.98(0.806)$ \\
\hline \multicolumn{5}{|c|}{ Histological Grade } \\
\hline II & 55 & $9.60(5.68-18.84)$ & $59.87(16.78-295.04)$ & $27.03(7.02-174.23)$ \\
\hline III & 2 & $15.01(8.57-27.10)$ & $149.13(28.96-302)$ & $40.17(17.94-95.76)$ \\
\hline $\mathrm{H}(\mathrm{p})$ & & $56.0(0.029)^{*}$ & $56.1(0.027)^{*}$ & $69.0(0.068)$ \\
\hline
\end{tabular}




\section{Continued}

\begin{tabular}{ccccc}
\hline \multicolumn{5}{c}{ Clinical Stage } \\
I & $1 \#$ & $8.09 \#$ & $26.35 \#$ & $16.67 \#$ \\
II & 18 & $7.68(5.68-9.02)$ & $24.68(16.78-35.04)$ & $17.75(8.73-26.05)$ \\
III & 11 & $7.17(6.06-9.02)$ & $21.53(17.22-36.35)$ & $16.38(7.15-23.28)$ \\
IV & 30 & $12.58(9.14-27.10)$ & $111.04(38.09-302)$ & $39.04(7.02-174.23)$ \\
H(p) & & $60(<0.001)^{*}$ & $60(<0.001)^{*}$ & $1.22(0.747)$ \\
& & Vascular Invasion & \\
Negative & 2 & $9.35(9.22-9.49)$ & $45.26(42.0-48.52)$ & $23.39(17.65-29.13)$ \\
Positive & 28 & $10.07(5.68-27.10)$ & $68.07(16.78-302)$ & $28.29(7.02-174.23)$ \\
U(p) & & $52.0(0.824)$ & $52.0(0.824)$ & $42.0(0.547)$ \\
& & Site of Metastasis & $48.75(0.195)$ \\
Bone & 9 & $14.64(9.02-18.49)$ & $146.40(36.35-257.22)$ & $48.02(7.43-105.01)$ \\
Lung & 8 & $12.62(9.49-15.94)$ & $117.92(48.52-253.30)$ & $37.06(7.02-56.34$ \\
Liver & 6 & $12.29(9.23-15.94)$ & $108.30(46.35-253.30)$ & $43.98(14.13-95.76)$ \\
Other sites & 7 & $10.17(9.22-81.57)$ & $60.07(42-81.57)$ & $25.55(7.02-81.56)$ \\
H(p) & & $7.91(0.048)^{*}$ & $7.05(0.070)$ & 4.70 \\
\hline
\end{tabular}

U: Mann Whitney test, H: H for Kruskal Wallis test. *: Statistically significant at $\mathrm{p} \leq 0.05$, \#: Excluded from the relation due to small number of case $(n=1)$.

IL-6 showed a significant association histological grade $(\mathrm{p}=0.029,0.027$ respectively) and clinical stage $(\mathrm{p}<0.001)$ (Figure 2). Spearman correlations also revealed a significant positive correlation between both markers with patients' histological grade $\left(r_{s}=0.282, p=0.029, r_{s}=0.284, p=0.028\right)$ and clinical stage $\left(r_{s}=0.789, p<0.001, r_{s}=0.788, p<0.001\right)$ for YBX-1 and IL-6 respectively.

Further investigation of the levels of YBX-1 and IL- 6 in metastatic group $(\mathrm{n}=$ $30)$ showed that they are further associated with lymph nodes involvement $(\mathrm{p}=$ $0.001,0.025)$ and vascular invasion $(p=0.046,0.003)$ as presented in Figure 3. Metastasis site-specific analysis showed a significant difference between YBX-1 level $(\mathrm{H}=7.91, \mathrm{p}=0.048)$, however, none of the major metastasis sites (Bone, lung and liver) showed a significant elevation than the other. Furthermore, no particular site of metastasis showed a significant elevation in IL-6 and CA 15-3 than the others $(\mathrm{H}=7.05, \mathrm{p}=0.070$ and $\mathrm{H}=4.70, \mathrm{p}=0.195$ respectively).

\subsection{Correlation of YBX-1 and IL-6 Serum Concentrations in BC Patients}

In the overall breast cancer patients $(n=60)$ the median YBX-1 serum levels was $9.08 \pm 0.50 \mathrm{pg} / \mathrm{ml}$ and IL-6 was $37.22 \pm 9.08$. IL-6 levels were elevated in patients with higher YBX-1 level. As shown in Figure 4, Spearman correlation between YBX-1 and IL-6 levels revealed that there was a significant positive correlation between the levels of both markers $\left(r_{s}=0.615, p<0.001\right)$. 


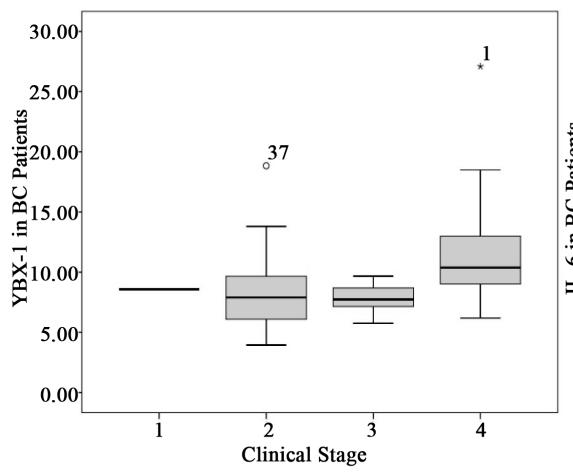

(a)

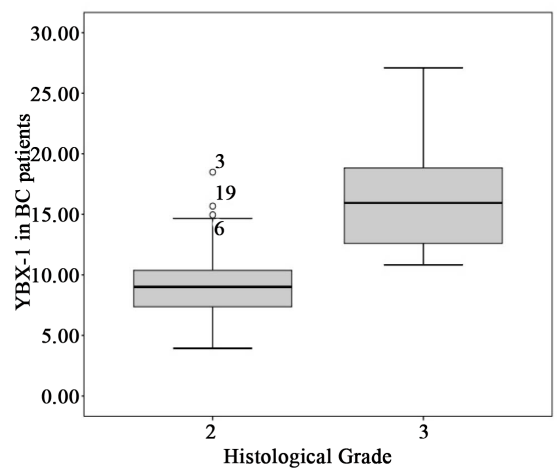

(c)

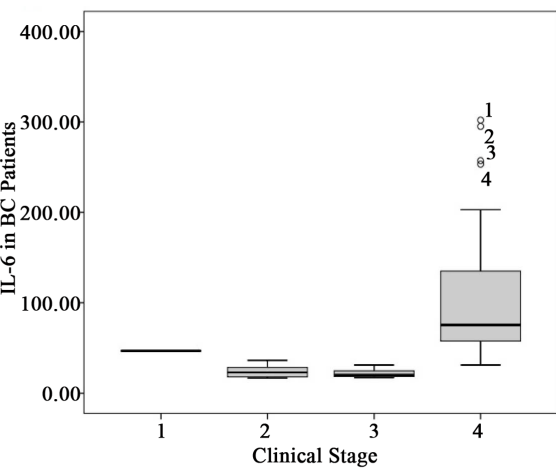

(b)

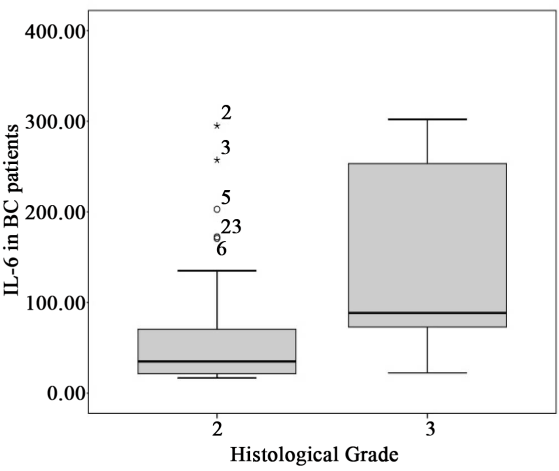

(d)

Figure 2. Correlations between Y-Boxl and IL-6 Levels with clinical stage ((a), (b)) and histological grade $((\mathrm{c}),(\mathrm{d}))$ in $\mathrm{BC}$ patients.

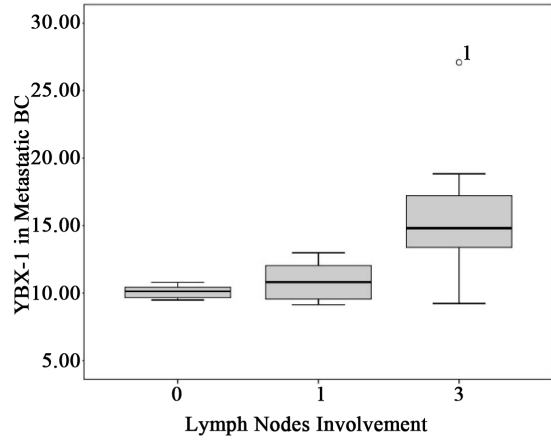

(a)

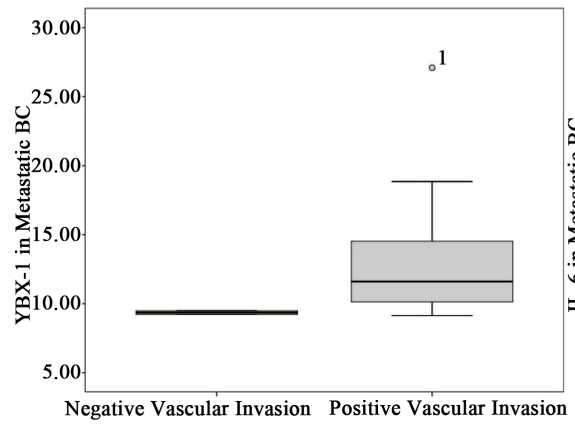

Vascular Invasion

(c)

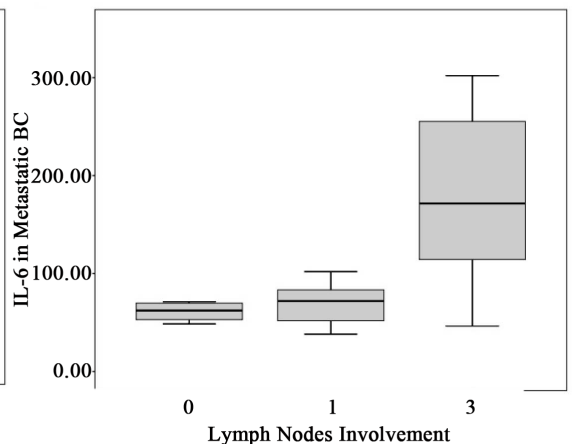

(b)

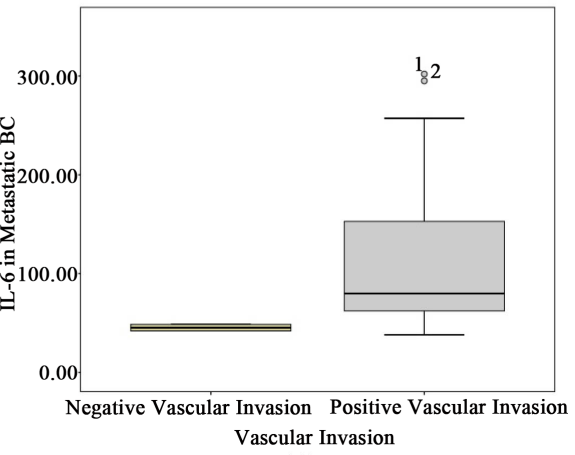

(d)

Figure 3. Association between Y-Box1 and IL-6 Levels with lymph nodes involvement ((a), (b)) and vascular invasion ((c), (d)) in metastatic BC patients. 


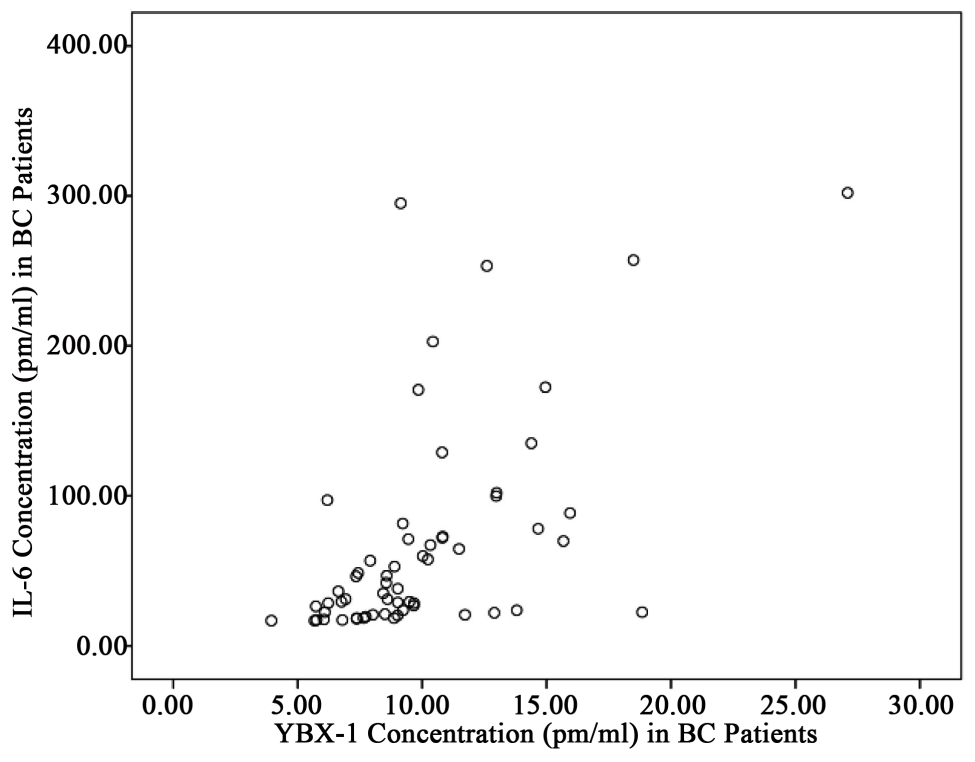

Figure 4. Correlation between Y-Box1 and IL-6 Levels in BC patients.

\subsection{YBX-1 and IL-6 Have Superior Sensitivity and Specificity over CA 15-3 in Predicting BC Metastasis}

Investigating the sensitivity and specificity of YBX-1 and IL-6 in predicting BC metastasis we constructed a ROC curve against CA15-3. The ROC curve for YBX-1 (Figure 5(a)) had an area below the curve of $0.892(\mathrm{p}<0.001)$ with confidence interval $(0.0826-0.958)$. The cut-off point, or Youden Index, was 8.5 $\mathrm{pg} / \mathrm{ml}$. The model has high specificity (79.3\%) and sensitivity (86.7\%). Regarding the IL-6, area below the curve was $0.996(\mathrm{p}=0.004)$ with confidence intervals $(0.988-1.000)$. The Youden index was $8.74 \mathrm{pg} / \mathrm{ml}$ with $100 \%$ sensitivity and $90.9 \%$ specificity (Figure $5(\mathrm{~b})$ ).

\section{Discussion}

Regardless of the current advances in diagnosis and treatment, recurrence and metastasis still threaten a high number of breast cancer patients and contribute to the high disease related mortality rates. In the present study, we primarily aimed to quantify serum levels of YBX-1 and IL- 6 in breast cancer patients compared to CA 15-3 which is routinely used to follow up BC patients. Our results showed that both YBX-1 and IL- 6 are significantly elevated in BC patients and their levels are even more elevated with cancer metastasis. On the other hand, although CA 15.3 was significantly elevated in both cancer groups, its levels in metastatic and non-metastatic patients were not significantly different.

The elevated levels of YBX-1 especially in metastatic BC patients is supported by the strong evidence on its role in breast cancer progression and aggressiveness. A meta-analysis showed that the patients with increasing YBX-1 expression are at high risk of relapse and metastasis compared with those with low YBX-1 expression [22]. Although most previous data focused on evaluating the nuclear and/or cytoplasmic expression of YBX-1 in tumor cells, very scarce studies have 


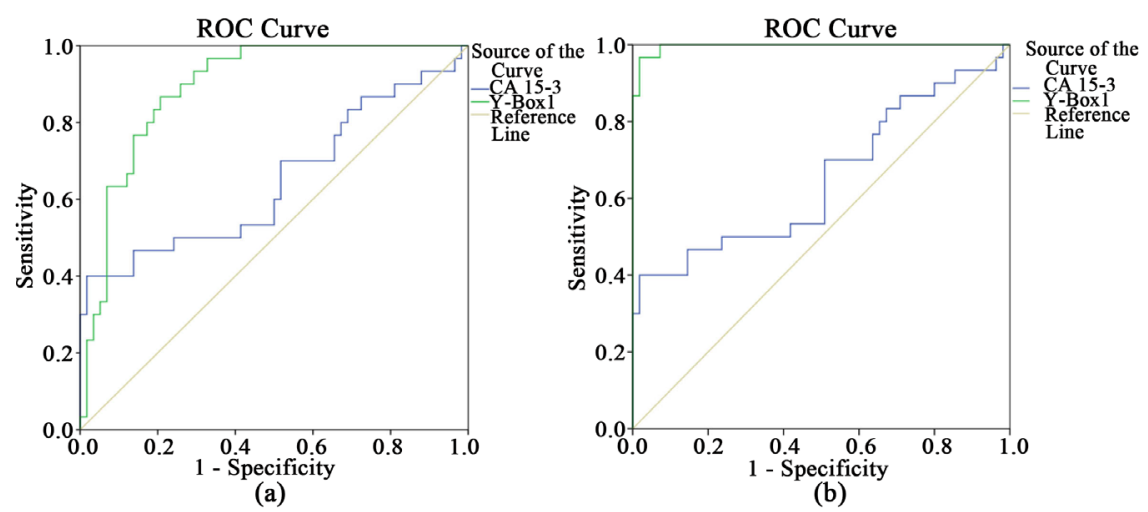

Figure 5. ROC curves for Y-Box1 and IL-6 levels against CA15-3 in metastatic BC patients.

focused on evaluating its serum levels. YBX-1 is secreted through anon-classical vesicle-mediated pathway, from mesangial and monocyticcells under lipopolysaccharide-induced inflammatory stress [23]. In 2014, Tacke et al. have reported that YBX-1/p-18 fragment is more prevalent in the plasma of patients with different malignancies including lung, breast and hematological malignancies [24]. Several studies have also supported the role of IL-6 in BC however their results were contradicting. Our results suggest that IL- 6 is associated with poor clinical outcome. These results are supported with the results of Ma et al. (2017) who reported the association of elevated serum IL-6 with poor prognosis [25]. Nevertheless, other reports have characterized IL-6 as a marker of good prognosis [26]. This apparent contradiction might be attributed to the difference in patients' stratification according to hormonal status. Studies conducted on patients with mixed ER/PR status showed similar results to ours unlike studies that focused on ER+ patients alone [27]. It worth notion that ER $\alpha+$ BC cells have been reported to produce minimal autocrine IL- 6 and are dependent on paracrine IL-6 from within the tumor microenvironment including that produced by bone fibroblasts and adipose tissue [9] [28]. IL-6 exerts its effects on ER $\alpha+$ $\mathrm{BC}$ cells via the phosphorylation of tyrosine 705 of signal transducer and activator of transcription (STAT) 3 and consequently, promotes growth and invasion [29].

As for the relation between YBX-1 and IL- 6 our results indicated a significant positive correlation between the two parameters. These results are supported by previous reports suggesting that IL-6 is a transcriptional target for YBX-1 activity [30]. The results of Castellana et al. supported that forced expression of YBX-1 increased IL- 6 levels in three BC cell lines by directly binding and stabilizing the short-lived mRNA of IL-6 [31]. The interplay between YBX-1 and IL-6 seems to create a positive feed-forward loop leading to the activation of EMTlike features of cancer cells, including increased motility thus promoting cell invasion and metastasis [32].

The significant elevation of YBX-1 and IL-6 in breast cancer patients was further analyzed by stratifying the patients according to their clinicopathological 
characteristics. Our results indicated that YBX-1 and IL-6 serum levels were significantly correlated to advanced histological grade and poor clinical stage in BC patients. Further analysis indicated that both parameters were significantly associated with increased lymph nodes involvement and positive vascular invasion in metastatic breast cancer patients which supports our hypothesis of their central role in cancer invasion and metastasis. In agreement with our results, Nuclear YB-1 expression was found to be correlated with disease stage, tumor diameter, stromal invasion, and lymph-node metastasis in cervical cancer. It was also found to be correlated with epithelial growth factor receptor expression which implies to its role in processes associated with tumor development and progression, such as cell growth, inhibition of apoptosis, cell migration, and angiogenesis [18]. YBX-1 expression level was also correlated with tumor grade and invasiveness in bladder carcinoma [33]. YBX-1 has also been reported to be associated with "stem cell-like" tumor phenotype based on retrospective immunehistochemical study of paraffin-embedded breast cancer tissues [34]. A recent study reported a co-elevation of serum YBX-1 and IL- 6 in breast cancer patients that was significantly correlated to bone metastasis [35].

Regarding the utility of YBX-1 and IL- 6 as clinical biomarkers, we analyzed their sensitivity and specificity in identifying metastatic breast cancer patients compared to CA 15-3 which is routinely used as a follow up and prognostic marker. Our results indicated that YBX-1 and IL-6 had significantly higher sensitivity and specificity than CA 15-3 which implies their potential role as prognostic markers for breast cancer. The prognostic role of YBX-1 and IL-6 has been referred to in a number of previous studies on various types of cancers including ovarian [36], prostate [37], acute lymphoblastic leukemia [38] and multiple myeloma [39]. However, most of these studies focused on analysis of either fresh or paraffin-imbedded tissues with few exceptions which focused on minimally invasive samples like serum or plasma [35] [40]. Our results therefore support the evidence that serum YBX-1 and IL- 6 levels can be used as valuable biomarkers of breast cancer with a strong potential of predicting metastasis.

Our study experienced some limitations including the small sample size, which might have caused less statistical power. Another limitation is that we didn't include disease-free and overall survival follow-up and analysis to allow a more detailed investigation of their prognostic significance. Therefore, further study with a larger sample size and patients' follow-up is needed.

\section{Conclusion}

From the results of this study, we can conclude that serum YBX-1 and IL-6 are potential biomarkers of breast cancer patients with significant correlation with poor clinicopathological characteristics. Serum YBX-1 and IL-6 have superior sensitivity and specificity compared to CA15-3 and can serve as a potential follow up and prognostic marker. 


\section{Conflicts of Interest}

The authors declare no conflicts of interest regarding the publication of this paper.

\section{References}

[1] Bray, F., Ferlay, J., Soerjomataram, I., Siegel, R.L., Torre, L.A. and Jemal, A. (2018) Global Cancer Statistics 2018: GLOBOCAN Estimates of Incidence and Mortality Worldwide for 36 Cancers in 185 Countries. Cancer, 68, 394-424. https://doi.org/10.3322/caac.21492

[2] Lyabin, D.N., Eliseeva, I.A. and Ovchinnikov, L.P. (2014) YB-1 Protein: Functions and Regulation. Wiley Interdisciplinary Reviews. RNA, 5, 95-110. https://doi.org/10.1002/wrna.1200

[3] Zasedateleva, O.A., Krylov, A.S., Prokopenko, D.V., Skabkin, M.A., Ovchinnikov, L.P., Kolchinsky, A., et al. (2002) Specificity of Mammalian Y-Box Binding Protein p50 in Interaction with ss and ds DNA Analyzed with Generic Oligonucleotide Microchip. Journal of Molecular Biology, 324, 73-87.

https://doi.org/10.1016/S0022-2836(02)00937-3

[4] Weydert, C., van Heertum, B., Dirix, L., De Houwer, S., De Wit, F., Mast, J., et al. (2018) Y-Box-Binding Protein 1 Supports the Early and Late Steps of HIV Replication. PLoS ONE, 13, e0200080. https://doi.org/10.1371/journal.pone.0200080

[5] Alemasova, E.E., Moor, N.A., Naumenko, K.N., Kutuzov, M.M., Sukhanova, M.V., Pestryakov, P.E., et al. (2016) Y-Box-Binding Protein 1 as a Non-Canonical Factor of Base Excision Repair. Biochimica et Biophysica Acta, 1864, 1631-1640. https://doi.org/10.1016/j.bbapap.2016.08.012

[6] Higashi, K., Inagaki, Y., Suzuki, N., Mitsui, S., Mauviel, A., Kaneko, H., et al. (2003) Y-Box-Binding Protein YB-1 Mediates Transcriptional Repression of Human Alpha 2(I) Collagen Gene Expression by Interferon-Gamma. The Journal of Biological Chemistry, 278, 5156-5162. https://doi.org/10.1074/jbc.M208724200

[7] Prabhu, L., Hartley, A.V., Martin, M., Warsame, F., Sun, E. and Lu, T. (2015) Role of Post-Translational Modification of the Y Box Binding Protein 1 in Human Cancers. Genes and Diseases, 2, 240-246. https://doi.org/10.1016/j.gendis.2015.05.001

[8] Lyabin, D.N., Doronin, A.N., Eliseeva, I.A., Guens, G.P., Kulakovskiy, I.V. and Ovchinnikov, L.P. (2014) Alternative Forms of Y-Box Binding Protein 1 and YB-1 mRNA. PLoS ONE, 9, e104513. https://doi.org/10.1371/journal.pone.0104513

[9] Nishio, S., Ushijima, K., Yamaguchi, T., Sasajima, Y., Tsuda, H., Kasamatsu, T., et al. (2014) Nuclear Y-Box-Binding Protein-1 Is a Poor Prognostic Marker and Related to Epidermal Growth Factor Receptor in Uterine Cervical Cancer. Gynecologic Oncology, 132, 703-708. https://doi.org/10.1016/j.ygyno.2014.01.045

[10] Panupinthu, N., Yu, S., Zhang, D., Zhang, F., Gagea, M., Lu, Y., et al. (2014) Self-Reinforcing Loop of Amphiregulin and Y-Box Binding Protein-1 Contributes to Poor Outcomes in Ovarian Cancer. Oncogene, 33, 2846-2856. https://doi.org/10.1038/onc.2013.259

[11] Guo, T., Yu, Y., Yip, G.W., Baeg, G.H., Thike, A.A., Lim, T.K., et al. (2015) Y-Box Binding Protein 1 Is Correlated with Lymph Node Metastasis in Intestinal-Type Gastric Cancer. Histopathology, 66, 491-499. https://doi.org/10.1111/his.12570

[12] Yan, X., Yan, L., Zhou, J., Liu, S., Shan, Z., Jiang, C., et al. (2014) High Expression of Y-Box-Binding Protein 1 Is Associated with Local Recurrence and Predicts Poor Outcome in Patients with Colorectal Cancer. International Journal of Clinical and 
Experimental Pathology, 7, 8715-8723.

[13] Eliseeva, I.A., Kim, E.R., Guryanov, S.G., Ovchinnikov, L.P. and Lyabin, D.N. (2011) Y-Box-Binding Protein 1 (YB-1) and Its Functions. Biochemistry, 76, 1402-1433. https://doi.org/10.1134/S0006297911130049

[14] Nagasu, S., Sudo, T., Kinugasa, T., Yomoda, T., Fujiyoshi, K., Shigaki, T., et al. (2019) Y-Box-Binding Protein 1 Inhibits Apoptosis and Upregulates EGFR in Colon Cancer. Oncology Reports, 41, 2889-2896. https://doi.org/10.3892/or.2019.7038

[15] Yang, J.Y., Ha, S.A., Yang, Y.S. and Kim, J.W. (2010) p-Glycoprotein ABCB5 and YB-1 Expression Plays a Role in Increased Heterogeneity of Breast Cancer Cells: Correlations with Cell Fusion and Doxorubicin Resistance. BMC Cancer, 10, 388. https://doi.org/10.1186/1471-2407-10-388

[16] Evdokimova, V., Tognon, C., Ng, T., Ruzanov, P., Melnyk, N., Fink, D., et al. (2009) Translational Activation of Snaill and Other Developmentally Regulated Transcription Factors by YB-1 Promotes an Epithelial-Mesenchymal Transition. Cancer Cell, 15, 402-415. https://doi.org/10.1016/j.ccr.2009.03.017

[17] Landskron, G., De La Fuente, M., Thuwajit, P., Thuwajit, C. and Hermoso, M.A. (2014) Chronic Inflammation and Cytokines in the Tumor Microenvironment. Journal of Immunology Research, 2014, Article ID: 149185. https://doi.org/10.1155/2014/149185

[18] Gyamfi, J., Eom, M., Koo, J.S. and Choi, J. (2017) Multifaceted Roles of Interleukin-6 in Adipocyte-Breast Cancer Cell Interaction. Translational Oncology, 11, 275-285. https://doi.org/10.1016/j.tranon.2017.12.009

[19] Zhang, S., Yang, X., Wang, L. and Zhang, C. (2018) Interplay between Inflammatory Tumor Microenvironment and Cancer Stem Cells. Oncology Letters, 16, 679-686. https://doi.org/10.3892/ol.2018.8716

[20] Sehgal, P.B. (2010) Interleukin-6 Induces Increased Motility, Cell-Cell and CellSubstrate Dyshesion and Epithelial-to-Mesenchymal Transformation in Breast Cancer Cells. Oncogene, 29, 2599-2600. https://doi.org/10.1038/onc.2010.4

[21] Sullivan, N.J., Sasser, A.K., Axel, A.E., Vesuna, F., Raman, V., Ramirez, N., et al. (2009) Interleukin-6 Induces an Epithelial-Mesenchymal Transition Phenotype in Human Breast Cancer Cells. Oncogene, 28, 2940-2947. https://doi.org/10.1038/onc.2009.180

[22] Wang, X., Guo, X.B., Shen, X.C., Zhou, H., Wan, D.W., Xue, X.F., et al. (2015) Prognostic Role of YB-1 Expression in Breast Cancer: A Meta-Analysis. International Journal of Clinical and Experimental Medicine, 8, 1780.

[23] Frye, B.C., Halfter, S., Djudjaj, S., Muehlenberg, P., Weber, S. and Raffetseder, U. (2009) Y-Box Protein-1 Is Actively Secreted through a Non-Classical Pathway and Acts as an Extracellular Mitogen. EMBO Reports, 10, 783-789. https://doi.org/10.1038/embor.2009.81

[24] Tacke, F., Galm, O., Kanig, N., Yagmur, E., Brandt, S., Lindquist, J.A., et al. (2014) High Prevalence of Y-Box Protein-1/p18 Fragment in Plasma of Patients with Malignancies of Different Origin. BMC Cancer, 14, 33. https://doi.org/10.1186/1471-2407-14-33

[25] Ma, Y., Ren, Y., Dai, Z.J., Wu, C.J., Ji, Y.H. and Xu, J. (2017) IL-6, IL-8 and TNFAlpha Levels Correlate with Disease Stage in Breast Cancer Patients. Advances in Clinical and Experimental Medicine, 26, 421-426.

https://doi.org/10.17219/acem/62120

[26] Milovanović, J., Todorović-Raković, N. and Radulovic, M. (2019) Interleukin-6 and Interleukin-8 Serum Levels in Prognosis of Hormone-Dependent Breast Cancer. 
Cytokine, 118, 93-98. https://doi.org/10.1016/j.cyto.2018.02.019

[27] Won, H.S., Kim, Y.A., Lee, J.S., Jeon, E.K., An, H.J., Sun, D.S., et al. (2013) Soluble Interleukin-6 Receptor Is a Prognostic Marker for Relapse-Free Survival in Estrogen Receptor-Positive Breast Cancer. Cancer Investigation, 8, 516-521. https://doi.org/10.3109/07357907.2013.826239

[28] Studebaker, A.W., Storci, G., Werbeck, J.L., Sansone, P., Sasser, A.K., Tavolari, S., et al. (2008) Fibroblasts Isolated from Common Sites of Breast Cancer Metastasis Enhance Cancer Cell Growth Rates and Invasiveness in an Interleukin-6-Dependent Manner. Cancer Research, 68, 9087-9095. https://doi.org/10.1158/0008-5472.CAN-08-0400

[29] Sasser, A.K., Sullivan, N.J., Studebaker, A.W., Hendey, L.F., Axel, A.E. and Hall, B.M. (2007) Interleukin-6 Is a Potent Growth Factor for ER-Alpha-Positive Human Breast Cancer. The FASEB Journal, 21, 3763-3770. https://doi.org/10.1096/fj.07-8832com

[30] Astanehe, A., Finkbeiner, M.R., Krzywinski, M., Fotovati, A., Dhillon, J., Berquin, I.M., et al. (2012) MKNK1 Is YB-1 Target Gene Responsible for Imparting Trastuzumab Resistance and Can Be Blocked by RSK Inhibition. Oncogene, 31, 44344446. https://doi.org/10.1038/onc.2011.617

[31] Castellana, B., Aasen, T., Moreno-Bueno, G., Dunn, S.E. and Ramón y Cajal, S. (2015) Interplay between YB-1 and IL-6 Promotes the Metastatic Phenotype in Breast Cancer Cells. Oncotarget, 6, 38239-38256. https://doi.org/10.18632/oncotarget.5664

[32] Grivennikov, S. and Karin, M. (2008) Autocrine IL-6 Signaling: A Key Event in Tumorigenesis? Cancer Cell, 13, 7-9. https://doi.org/10.1016/j.ccr.2007.12.020

[33] Song, Y.H., Shiota, M., Yokomizo, A., Uchiumi, T., Kiyoshima, K., Kuroiwa, K., et al. (2014) Twist1 and Y-Box-Binding Protein-1 Are Potential Prognostic Factors in Bladder Cancer. Urologic Oncology, 32, 31.e1-7. https://doi.org/10.1016/j.urolonc.2012.11.003

[34] Zhu, X., Tao, L., Yao, J., Sun, P., Pei, L., Li, J., et al. (2014) Identification of Collaboration Patterns of Dysfunctional Pathways in Breast Cancer. International Journal of Clinical and Experimental Pathology, 7, 3853-3864.

[35] Ferreira, A.R., Bettencourt, M., Alho, I., Costa, A.L., Sousa, A.R. and Mansinho, A. (2017) Serum YB-1 (Y-Box Binding Protein 1) as a Biomarker of Bone Disease Progression in Patients with Breast Cancer and Bone Metastases. Journal of Bone Oncology, 6, 16-21. https://doi.org/10.1016/j.jbo.2017.01.002

[36] Huang, X., Ushijima, K., Komai, K., Takemoto, Y., Motoshima, S., Kamura, T. and Kohno, K. (2004) Co-Expression of Y Box-Binding Protein-1 and P-Glycoprotein as a Prognostic Marker for Survival in Epithelial Ovarian Cancer. Gynecologic Oncology, 93, 287-291. https://doi.org/10.1016/j.ygyno.2004.01.040

[37] Abd El-Maqsoud, N.M., Osman, N.A., Abd El-Hamid, A.M., Fath El-Bab, T.K. and Galal, E.M. (2016) Golgi Phosphoprotein-3 and Y-Box-Binding Protein-1 Are Novel Markers Correlating with Poor Prognosis in Prostate Cancer. Clinical Genitourinary Cancer, 14, e143-e152. https://doi.org/10.1016/j.clgc.2015.12.015

[38] Kariminia, A., Ivison, S.M., Leung, V.M., Sung, S., Couto, N., Rozmus, J., et al. (2017) Y-Box-Binding Protein 1 Contributes to IL-7-Mediated Survival Signaling in B-Cell Precursor Acute Lymphoblastic Leukemia. Oncology Letters, 13, 497-505. https://doi.org/10.3892/ol.2016.5437

[39] Chatterjee, M., Rancso, C., Stühmer, T., Eckstein, N., Andrulis, M., Gerecke, C., et al. (2008) The Y-Box Binding Protein YB-1 Is Associated with Progressive Disease 
and Mediates Survival and Drug Resistance in Multiple Myeloma. Blood, 111, 3714-3722. https://doi.org/10.1182/blood-2007-05-089151

[40] Rohr, I., Braicu, E.I., En-Nia, A., Heinrich, M., Richter, R., Chekerov, R., et al. (2016) Y-Box Protein-1/p18 as Novel Serum Marker for Ovarian Cancer Diagnosis: A Study by the Tumor Bank Ovarian Cancer (TOC). Cytokine, 85, 157-164. https://doi.org/10.1016/j.cyto.2016.06.021 